\title{
Holistic approach of Ayurveda and Yoga can be the answer for the lifestyle disorders of present era
}

\section{Conceptual Paper}

Health is state of complete physical, mental and social wellbeing not merely an absence of disease or infirmity. Swastha is the word used in Ayurveda to denote health; it means maintain the equilibrium of Dosha, Dhatu and Mala with the proper functioning of aatma, indriya and mana in the body. Yoga connects the Mind with the body to maintain the Health. But Prevalence of Lifestyle disorder shooting up in the present era and positive health become questionable statistics says after the age of 40 , prevalence of lifestyle disorders are more than $50 \%$.

Faulty diet and Lifestyle changes are the main culprits to develop the Lifestyle disorders such as Obesity, Coronary heart diseases, Dyslipidaemia, Diabetes mellitus, Hypertension, Anaemia and some mental disorders. Ayurveda is the Life Science gives more importance to the Prevention of the Disease and Protection of the Health. Diet regimen, daily regimen, Night regimen and seasonal regimen are the different concept which is told in Ayurveda classics which is very much suitable in the present scenario.

\section{Prevention of Lifestyle disorders through Diet}

a. Avoid excess use of Dairy products and oily foods.

b. Avoidance of Alcoholic beverages and Tobacco.

c. Avoidance of junk food.

d. Limitation for sugary products.

e. Follow prudent diet. i.e Total fat intake restricted to $20-25 \%$ of total energy, daily salt intake restricted to $5 \mathrm{gm}$, Carbohydrate and fibre rich food intake.

f. Food should be taken depending upon the Digestive capacity of the Person.

g. Heavy food stuffs should be taken half of the satiety and Light food can be taken up to the Satiety but not more than that.

h. Classics say half of the stomach should be filled with solid foods, one fourth should be filled with liquid food and remaining one fourth should be kept empty for the movement of Air.

Prevention of lifestyle disorders through lifestyle changes

a. Daily regimens like wakening up Early in the morning-one and half hour before sunrise. It gives Nasant Oxygen, good concentration and good Health.

b. Drinking lukewarm water in the early morning, Practice of medicated oil massage, yogasana and physical exercise.

c. Undergo seasonal Purificatory procedure i.e Preventive Panchakarma to eliminate the Vitiated Doshas. (Vamana, Virechana, Basti, Nasya,Raktamokshana)
Volume II Issue 2 - 2018

\author{
Nagraj G Bhat \\ Department of Swasthavritta, SDMCA Udupi, Karnataka, India \\ Correspondence: Nagraj G Bhat, Department of \\ Swasthavritta, SDMCA Udupi, Karnataka, India, \\ Email: nagarajayu@gmail.com \\ Received:September 04, 2017 | Published: April 13, 2018
}

\section{Prevention of lifestyle disorders through mental factors}

a. Positive thinking.

b. Do well for others.

c. Follow Achara rasayana-code of conducts

d. Sadvritta palana-following righteous things

e. Not involving Harmful activities.

\section{revention of lifestyle disorders through yoga}

a. Follow Yama(personal ethics), Niyama(social ethics) to maintain personal and social health.

b. Practice of yogasana helps to reduce the excess of fat accumulated in the body.

c. Anuloma viloma Pranayama helps to maintain the equilibrium of body and mind, also beneficial in Respiratory disorders.

d. Meditation helps for concentration and control over senses.

\section{Conclusion}

Lifestyle disorders are result of what we eat and what we think. Good balanced diet and mental equilibrium are necessary to lead a disease free life. Concept of Ayurveda and Yoga if Practiced together it can make tremendous change in the Spectrum of Health. The big threat for the future of Health is Lifestyle disorder or Non communicable disease. Holistic approach of Ayurveda and Yoga will be the answer for this.

\section{Acknowledgment}

None

\section{Conflict of interest}

Author declares there is no conflict of interest towards publication of this manuscript. 